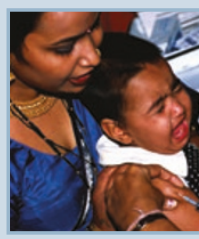

p154 Needless shots: Are health agencies pushing unnecessary vaccines in developing countries?

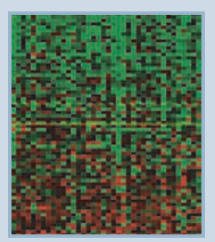

p158 Crystal chips:

Can microarrays

accurately predict

the outcome of

cancers?

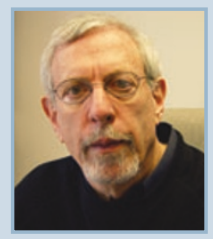

p160 Beer or biology?

At a pub in Denver, immunologist John

Cohen offers insights

into science.

\title{
Earlier drug tests on people could be unsafe, critics warn
}

The US Food and Drug Administration (FDA) in January announced a significant loosening of the rules that govern at what stage experimental drugs can first be tested in people. The changes are intended to speed up drug development, but critics say they might expose research participants to unwarranted danger.

The FDA's announcement comes as the embattled agency, which has been without a permanent leader for more than three of the last five years, is trying to salvage its tarnished public image. On 18 January, the agency also unveiled a long-awaited overhaul of druglabeling guidelines, intended to make the labels more accessible to doctors and consumers. Those won wide praise, but also raised a thorny legal issue involving lawsuits against drug makers.

The new rules on drug development will allow scientists to test small doses of experimental drugs in people before full-scale clinical trials begin, and before standard in vitro and animal tests are complete. The idea is that companies would be able to identify failing candidates and jettison them before they invest millions of dollars in costly clinical trials. The data from these early human studies might also help them design smarter trials for promising drugs.

A parallel set of guidelines on manufacturing will allow smaller companies and academic labs to make modest amounts of experimental drugs without the financial investment needed to meet industrial-scale manufacturing standards. Under previous guidelines, only companies with substantial resources were able to make drugs for human clinical trials.

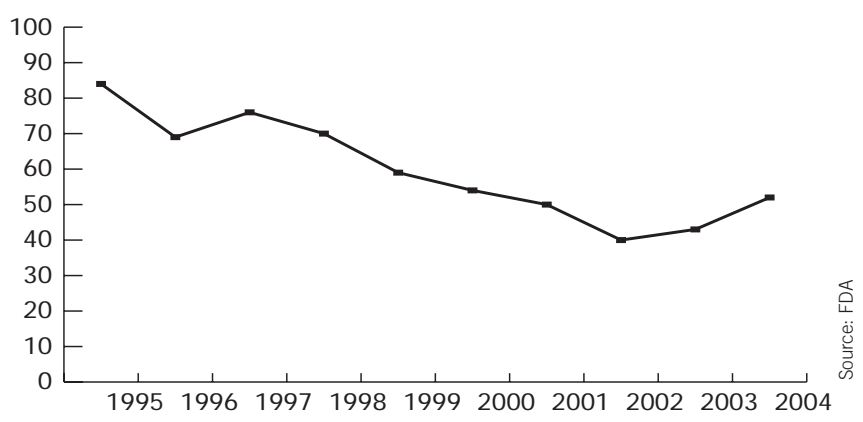

Drugs in decline: The new rules on drug testing are intended to reverse the decrease since 1995 in the number of candidates submitted for approval.
With the manufacturing changes, academic researchers will get much more information about these compounds early on, says Janet Woodcock, the agency's deputy commissioner for operations. "And the industrial sector will have a much broader range of compounds to evaluate coming out of academic labs," she adds.

Much of the response to the changes has been optimistic.

"I think this is a very positive, realistic step by the agency," says Raymond Woosley, chief executive officer of the Arizona-based C-Path Institute, a nonprofit that aims to speed drug development. "With small companies, it may make the difference between the life and death of the company or of the potential therapy," he says.

Woosley and others see the changes as a step toward fixing a broken model of drug development.

Since 1995, the number of new drug candidates brought to the FDA for approval has fallen dramatically (see graph) even as the drug industry has doubled its investment in drug development. About nine out of ten drugs that appear safe and effective in laboratory and animal tests fail in subsequent clinical studies.

The new rules would allow scientists to give low doses of an experimental drug for seven days or less to a small number of individuals. These 'exploratory' studies would not test the drug's safety or effectiveness, but would assess how it acts in the body and is metabolized. Based on how rapidly it is broken down, for instance, scientists could quickly identify and discard inappropriate candidates.

The drug giant Pfizer, in consultation with the FDA, in September 2005 conducted a pilot study in eight volunteers to evaluate the effects of a candidate anticoagulant. Testing the drug early in people shaved five months off the development time, says Liam Ratcliffe, senior vice president of global clinical research and development at Pfizer. Equally important, he says, the study allowed the company to determine the dose-response relationship, a key piece of information for deciding whether and how to move forward with a drug candidate.

Still, not everyone is convinced that the changes are completely positive.

"It's no secret that the FDA is too cozy with the drug industry, so I'm concerned for those who will be receiving these experimental drugs," Republican Senator Charles Grassley said in a statement.

"The whole purpose of preclinical studies is to ensure that the drug is safe enough to put in humans," adds Sidney Wolfe, a physician and director of health research at the Washington, DC-based advocacy group Public Citizen. "If you do fewer safety checks, there are more possibilities that the drug will not be safe enough when it goes into people," he says.

But that criticism is misplaced, say supporters of the new rules. "If you're Sid Wolfe, you only see the increased risk," says Woosley. "But if you're a patient who is sitting there waiting for a medicine to solve their health problem, you want people taking acceptable risks as often as possible."

Separately, the agency also came under fire for announcing - in conjunction with the new drug-labeling guidelines-that people injured by FDA-approved drugs that meet the agency's labeling requirements should not be able to sue the drug's makers in state courts. Companies have argued that the labeling changes open them to increased legal liability, and that they should in return receive more explicit federal protection from lawsuits.

Scott Gottlieb, the agency's deputy commissioner for medical and scientific affairs, says state courts don't have the scientific knowledge to second-guess the FDA's decisions. "I would say this is not a new policy position for the agency," he says. But critics say the FDA is protecting industry at the expense of consumers.

Meredith Wadman, Washington, DC

For more news and analysis go to news@nature.com www.nature.com/news 